\title{
An Investigation on Drying Process in a Novel Configuration of Fluidized Bed
}

\author{
در اسة عملية على عملية التجفيف في تكوين غير مألوف من المهد المميع.
}

Abdelsamed Ghazi Rashid, Hegazi A. A. and Okasha F.

Mechanical Power Engineering Dept., Faculty of Engineering, Monsoura

University, Monsoura, Egypt

Email: ahmedabd_elsallam@yahoo.com

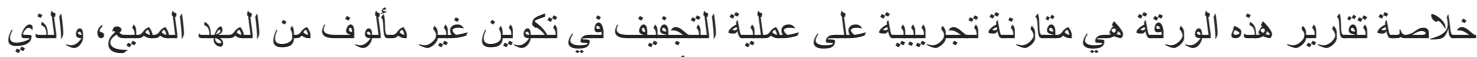

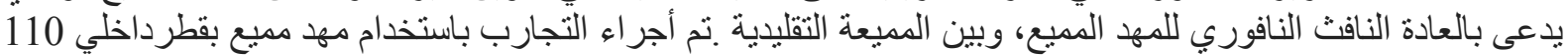

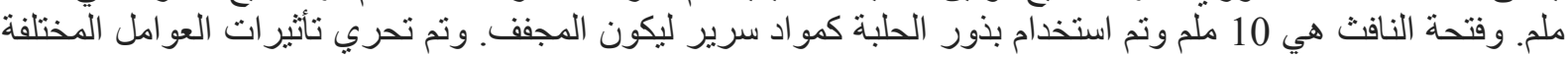

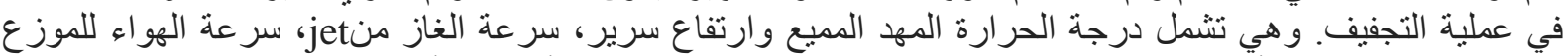

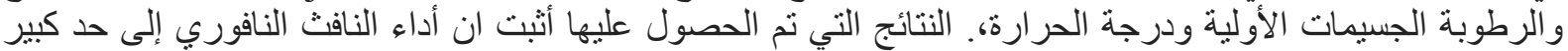
أفضل مقارنة بالتقليدية المميعة. و اثثبت ان التكوين النافوري ذاتجة ذات معدلات تجفيف أكبر و أكثر كفاءة في استخدام الطاقة. وترد مناقثة مزيد من التفاصيل داخل النص.

\section{Abstract}

This paper describes an experimental study on drying process in a novel configuration of fluidized bed, namely jetting fountain fluidized bed, and in conventional fluidized bed as well. The experiments have been carried out using a fluidized bed of $105 \mathrm{~mm}$ inner diameter. Fenugreek seeds have been used as bed materials to be dried. The influences of different parameters on drying process have been investigated. Those include bed temperature, air fluidization velocity, and jet air ratio and jet height. The experimental results demonstrate that the drying rate increases with the increase in jet air ratio and inlet air temperature. Jetting fountain configuration enables greater drying rates compared to conventional operation.

\section{Keywords}

Fluidized bed, drying, Fenugreek seeds.






\section{Introduction}

Fluidized bed dryers are widely used for the drying of wet particulates and granular materials that are able to be fluidized. They are frequently used in treatment many products to give an example, carbohydrates, foodstuff and chemicals. In order to obtain the best performance of a dryer, it is necessary that the operational conditions and the material to be dried are correctly specified. The operating conditions naturally influence the quality of the dried product. For drying powders rate decreased or when fraction of recycled air increased.

Oluwaleye [2] conducted the experimental evaluation of a batch hot air fluidized bed dryer for cassava particles. The resident drying time for cassava particles in the dryer was found to decrease with the increase in drying temperature. It was also observed that the drying rate decreases with the increase in air flow rate while it increases with drying temperature.

Khorshidi and Davari [3] investigated the effect of initial parameters such as inlet gas temperature, initial particles temperature and gas velocity on temperature changes of solid particles and outlet gas temperature in a fluidized bed dryer containing Colza seeds. Results showed that the maximum solid particles temperature variation and outlet gas temperature variation occur at the beginning of fluidization which shows high heat transfer in these kinds of dryers.

Simmonds et al. [4] investigated drying of granular products in a circulation dryer and found that the rate of drying was independent of the air velocity in the range of $1.64 \mathrm{~m} / \mathrm{s}$ to $8.74 \mathrm{~m} / \mathrm{s}$. The rate of drying was proportional to the free moisture content of the grain, while the grain temperature was related to the moisture content at any certain stage in the drying process.

João et al. [5] analyzed pressure effect on heat transfer coefficient between fluidized bed and a suspended surface. in the particle size range of 55 to $2100 \mu \mathrm{m}$, fluidized beds compete successfully with other more traditional dryer types, e.g., rotary, tunnel, conveyor, continuous tray.

Soponronnarit et. al, [1] presented an experimental study of paddy drying by fluidization technique. Air flow rate and air temperature affecting product quality, drying capacity and energy consumption were investigated. Experimental results showed that drying rate of a paddy kernel was controlled by diffusion. Energy consumption was reduced when air flow

The results showed that heat transfer coefficient between a bed and a suspended surface increased as bed pressure enhanced. Also results proved that pressure effect on heat transfer coefficient reduced as particle size is decreased.

Bosteels et al. [6] presented an experimental study on a fluidized bed dryer for processing Artemia cysts at temperature above $40{ }^{\circ} \mathrm{C}$. Applying the inflow air temperature up to $90{ }^{\circ} \mathrm{C}$ ensures a higher drying rate, resulting in a drying capacity more than 4 times higher than when using inflow air temperature of 40 ${ }^{\circ} \mathrm{C}$.

Srinivas and PydiSetty [7] investigated the drying behavior of different uniformly sized particles as well as various binary mixtures of solids with different dilutions of fine size particles with coarse particles with different pairs of uniformly sized particles. It is noticed that for both uniformly sized particles and different binary mixtures, drying rate is found to increase with increase in air velocity, temperature and decrease with increase in diameter of the particles, initial moisture content of solids and initial bed height of solids. The drying rates are found to be highest for ten percent binary mixture compared with uniformly sized particles and other binary mixtures and lowest for forty percent binary mixture. This indicates that the dilution beyond thirty percent is not beneficial. 
Nazghelichi et al. [8] studied thermodynamic analysis of fluidized bed drying of carrot cubes. The effects of drying variables on energy utilization, energy utilization ratio, exergy loss and exergy efficiency were studied. The results showed that small particles, deep beds and high inlet air temperatures increased energy utilization, energy utilization ratio, and exergy loss due to high value of heat and mass transfer. Also, the exergy efficiency had maximum value when higher drying air temperature, larger cube size and shorter bed depth used for drying experiment.

The aim of the present work is to perform an experimental study on drying process in a novel configuration of fluidized bed, namely jetting fountain fluidized bed. The novel configuration was developed by Okasha and presented in various articles [9-15]. It is principally a bubbling fluidized bed furnished with a spouted jet issuing in the upper part of the bed, see Fig. 1. A quantity of air is introduced through a jet pipe. The remaining air is fed via the distributor plate to fluidize bed solids. Jettingfountain configuration is characterized by excellent gas-solids contact. This feature is thanks to creating a jet in the upper part of the bed, establishing a fountain in the freeboard and moderating bubbles size in the main bed. Different advantages of the novel configuration can be found in the literatures [9-15]. The novel configuration has been applied for drying fenugreek seed. The drying rate has been evaluated by measuring humidity difference of fluidizing air. The influences of operating parameters on the drying rate have been assessed. Comparisons with conventional operation have been also given.

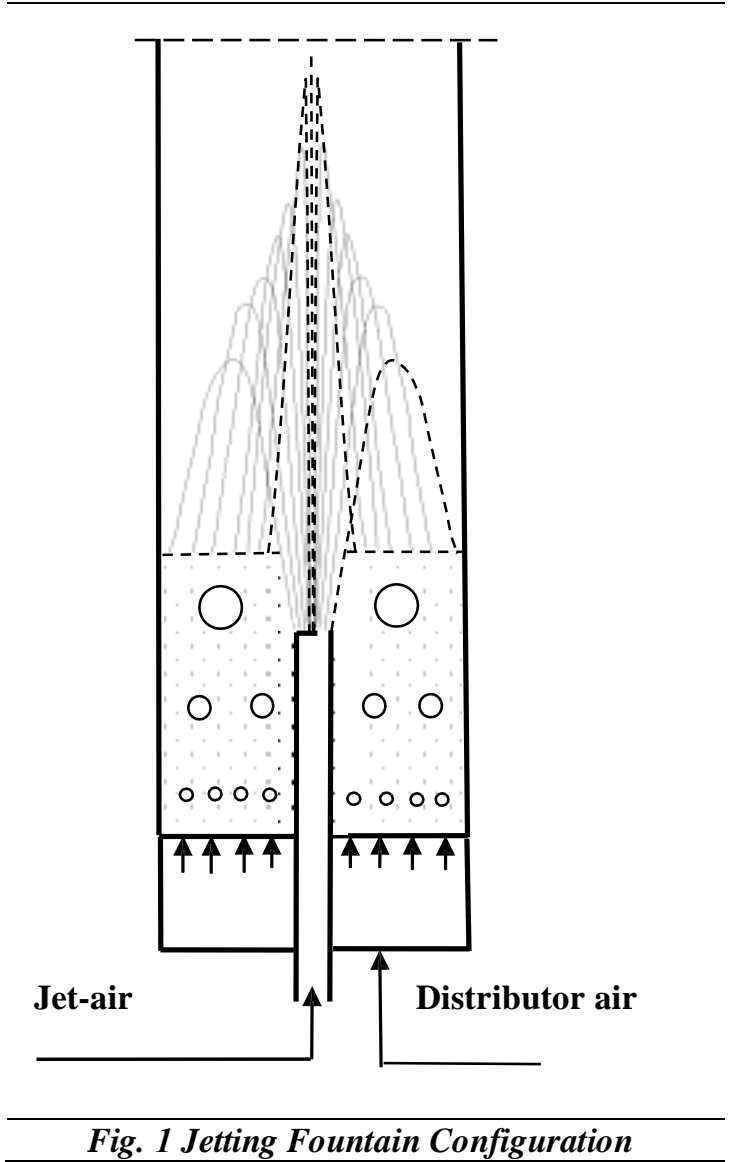

\section{Experimental set up}

A schematic diagram of the experimental set up is shown in Fig. 2. It mainly consists of a fluidization column, electric heaters, a compressor and measurement devices. The fluidization column (3) is made of stainless steel with an inside diameter of $105 \mathrm{~mm}$ and an overall length of $7000 \mathrm{~mm}$. A perforated type plate is used to distribute the primary air at the bottom of the fluidization column. The air serves in fluidizing and drying bed materials. A stainless steel tube of $10 \mathrm{~mm}$ inner diameter is used to feed jet-air vertically upward. It passes through the fluidization column. The tube is designed to be movable in vertical direction in order to adjust the location of the jet outlet regarding the distributor plate and bed surface.

The flow rate of distributor air is measured using a calibrated orifice meter while the flow rate of the jet air is 
measured using a rotameter. Inlet and outlet humidity of the air are measured using a humidity sensor (DHT22). Two electric heaters, $2 \mathrm{KW}$ each, are used to preheat distributor and jet air

The bed temperature is measured by thermocouples type K. The pressure drop across bed is measured by U-tube manometer.

In this experimental study, fenugreek seeds are used as the test material to be dried. The physical properties of fenugreek seeds used in the experiments are shown in Table 1.
Table 1 physical properties of fenugreek seeds

\begin{tabular}{|l|l|}
\hline Average spherical diameter & $2-2.36 \mathrm{~mm}$ \\
\hline Density & $1442 \mathrm{~kg} / \mathrm{m}^{3}$ \\
\hline Minimum fluidization velocity & $0.695 \mathrm{~m} / \mathrm{sec}$ \\
\hline
\end{tabular}

\section{Results and Discussion}

A series of experimental tests have been performed to investigate dying of fenugreek. It gives a comparison between the jetting-fountain configuration and the conventional operation. In the conventional operation all air is fed through the gas distributor.

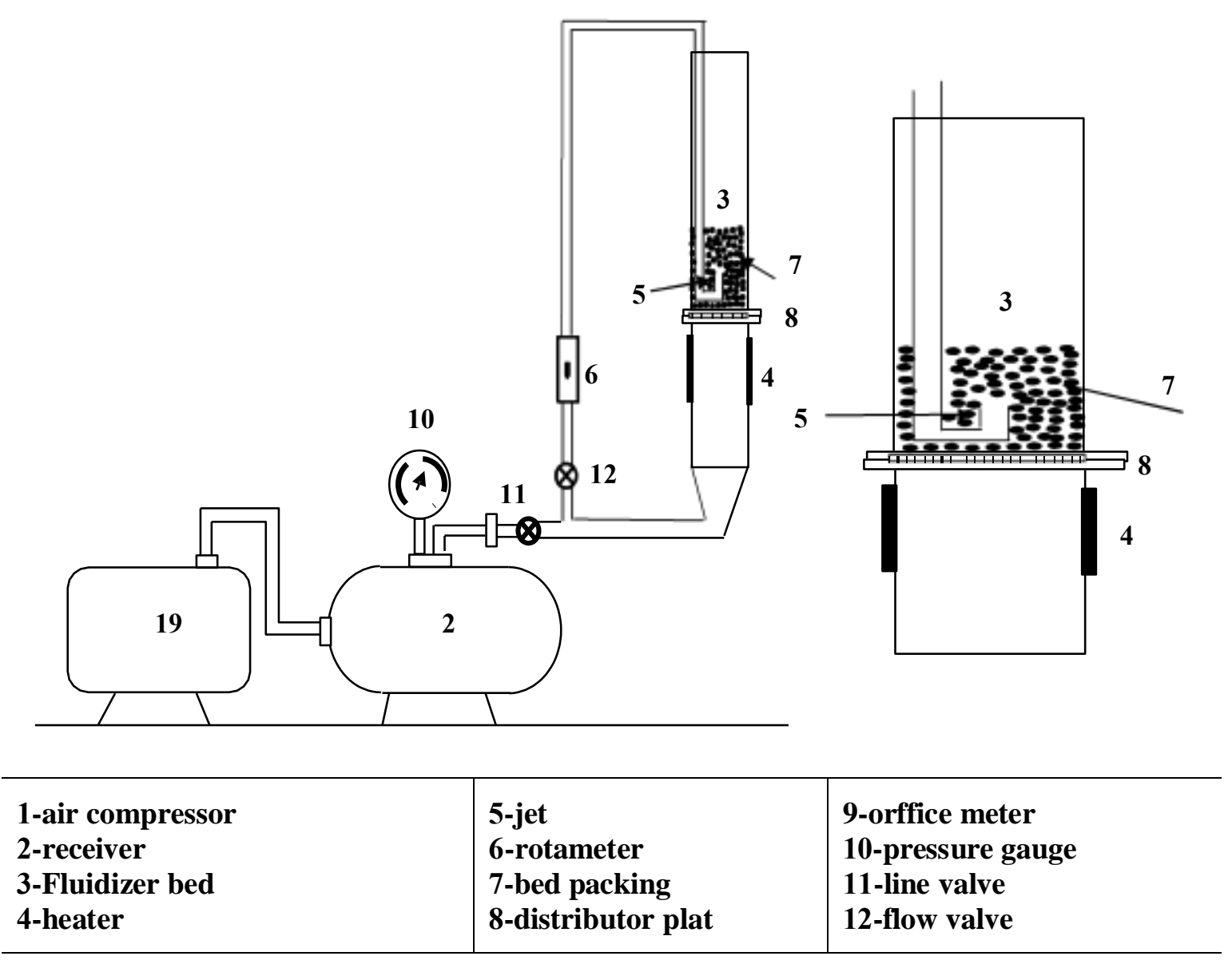

Fig. 2 Experimental set up 
On the other hand, in the jetting fountain fluidized bed, only a part of air is fed through the distributor. While the second part of air, called jet air, is fed via the jet pipe creating a large fountain zone in the freeboard. However, the total fed air rate is maintained the same in the jetting fountain configuration and the corresponding conventional operation test. Jet air ratio, JR is defined as the mass ratio of jet air rate to the total air rate. Mathematically, it may be expressed as:

$J R=\frac{\text { jet air rate }}{\text { jet air rate+distributor air } r}$

In all tests the static bed height is fixed to $25 \mathrm{~cm}$.

The drying rate is estimated considering that the increase in air moisture content is equal to the loss in fenugreek seeds moisture content. The following expression is used to calculate air moisture content, $\mathrm{w}$,

$W=0.622 \frac{\varphi \rho_{v}}{1.013-\rho_{v}}\left[\frac{\mathrm{kg} \text { of water }}{\mathrm{kg} \text { of dry air }}\right]$

Where $\varphi$ is the relative humidity and $p_{v}$ is the saturation pressure corresponding the measured temperature. The moisture transfer rate $\left(\mathrm{m}_{\mathrm{v}}\right)$ is obtained by:

$m_{v}=m_{d}\left(w_{0}-w_{i}\right)\left[\frac{\mathrm{kg} \text { of water }}{\sec }\right]$

The total moisture loss over a drying period $\mathrm{t}$ is calculated by:

$M L=\int_{o}^{t} m_{v} \cdot d t[k g]$

A typical drying rate curve is shown in Fig.3. The drying rate is plotted as a function of time. It is obvious that the drying rate curve has two distinct periods. The first period has a falling drying rate where drying rate is dependent on both of external and internal mass transfer resistances. The second period has a constant drying rate. During the later period the drying rate appears to be only internal mass transfer controlled.

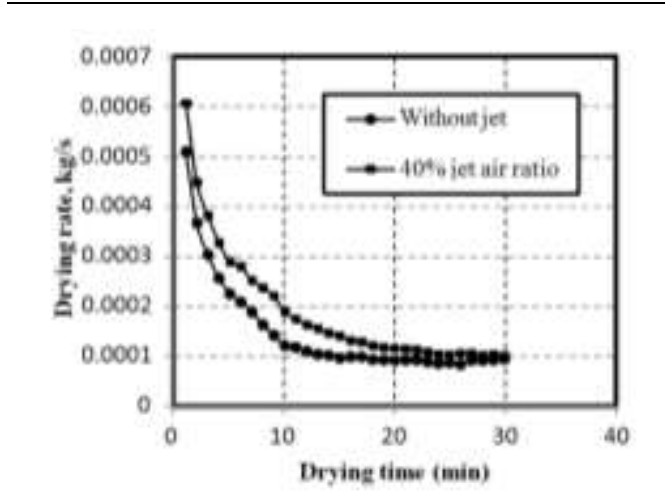

Fig. 3 Drying rate versus drying time without $/$ with $J R=40 \%$ for $h b=25 \mathrm{~cm}$ and

$T_{i}=60^{\circ} \mathrm{C}$

\section{Effect of air velocity}

Effect of air velocity on drying process has been studied at three different velocities of $1.5,2$ and $2.5 \mathrm{~m} / \mathrm{sec}$ while inlet air temperature was maintained at 60 ${ }^{\circ} \mathrm{C}$.

Fig. 4 shows the moisture loss in the fenugreek particles versus time at various inlet air velocities in the case of conventional operation, i.e. without air jet. The results indicate that increasing air fluidization velocity increases the moisture loss. The findings appear realistic since at higher fluidization velocity the air flow rate is greater, and in turn, the air is able to carry more moisture to reach the same humidity.



Fig. 4 Moisture loss versus drying time at various air fluidization velocity for $h_{b}=$ $25 \mathrm{~cm}$ and $\mathrm{T}_{\mathrm{i}}=60^{\circ} \mathrm{C}$ 
Fig. 5 shows the moisture loss in the fenugreek particles versus air fluidization velocity. The figure gives a comparison between the conventional operation and jetting fountain operation with $40 \%$ jet air ratio. The presented, results demonstrate that jetting fountain configuration performs better than conventional operation. Specifically, the moisture loss increases by $18.87 \%$, $30.33 \%$ and $28.2 \%$ at air velocity of 1.5 , $2,2.5 \mathrm{~m} / \mathrm{s}$, respectively. It is obvious that jetting fountain configuration enhances mass transfer due to creating a jet in the upper part of the bed, establishing a fountain in the freeboard and moderating bubbles size in the main bed.

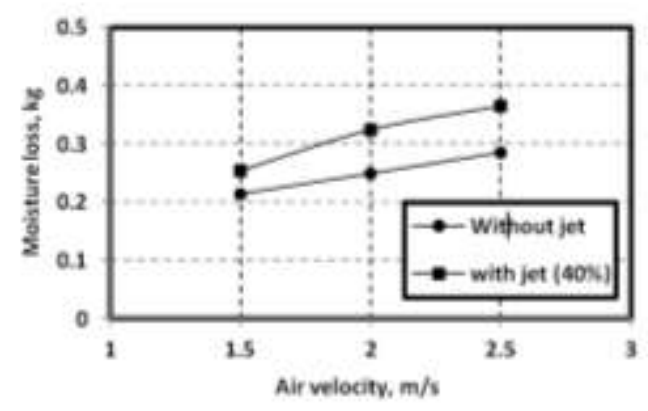

Fig. 5 Moisture loss versus air fluidization velocity without/with $J R=40 \%$ for $t_{d}=30 \mathrm{~min}$.

\section{Effect of inlet air temperature}

Effect of inlet air temperature on drying process has been tested at three different temperatures of 40, 60 and 80 ${ }^{\circ} \mathrm{C}$. Fig. 6 shows the moisture loss in the fenugreek particles versus time at various inlet air temperatures in the case of conventional operation. It is evident that increasing the inlet air temperature increases the drying rate and moisture loss. This appears reasonable as increasing the particle temperature increases the moisture vapor inside that results in an increase in the driving force for moisture transfer.

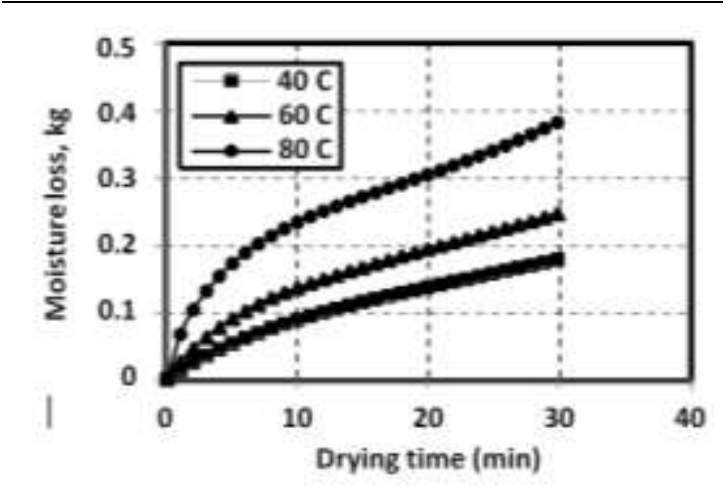

Fig. 6 Moisture loss versus drying time at
various inlet air temperature for $h_{b}=25 \mathrm{~cm}$
and $u_{i}=2 \mathrm{~m} / \mathrm{s}$

Fig. 7 shows the moisture loss of the fenugreek particles versus inlet air temperature. The figure compares the findings of conventional operation with that of jetting fountain configuration with $40 \%$ jet air ratio. The findings illustrate that jetting fountain configuration enables greater moisture loss for all considered temperature, in particular, at higher temperature. As discussed above applying jetting fountain configuration enhances the external mass transfer that appears have a higher impact at higher temperature.

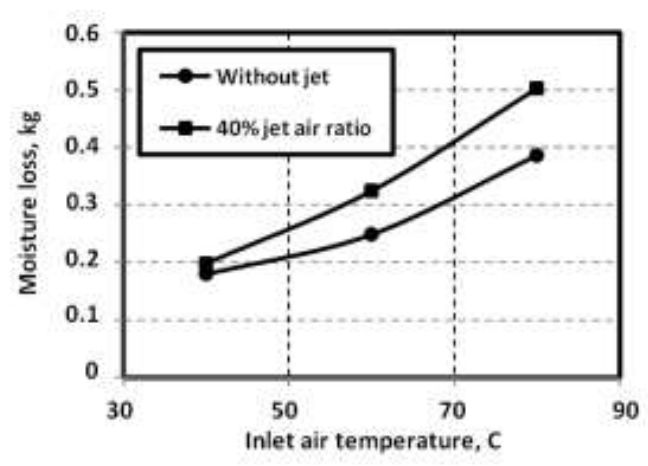

Fig. 7 Moisture loss versus inlet air temperature without/with $J R=40 \%$ for $t_{d}=30$ min.

\section{Effect of jet air ratio}

In jetting fountain configuration a part of air is fed through the jet pipe to create a fountain of particles. Jet air ratio is used to express the fraction of air that is 
delivered via the jet pipe as discussed above. Fig. 8 illustrates the influence of jet air ratio on the drying rate and moisture loss. It appears worth to indicate that the conventional operation of fluidized bed is the case at $\mathrm{JR}=0$. The data presented in Fig. 8 reveal that increasing JR improves the drying process and increases the moisture loss. However, the moisture loss attains a maximum at $40 \% \mathrm{JR}$, and then deceases for higher values as shown in Fig.9.It appears that the beneficial of increasing contact efficiency due to creating a fountain and decreasing bubbles sizes start be off set. At high jet air ratio, the jet velocity becomes very high that decreases the air contact time. Moreover, under this condition a large fraction of air bypasses the lower part of the bed without contact. However, lowering the jet orifice down in the bed could allow higher jet air ratio with greater contact efficiency.

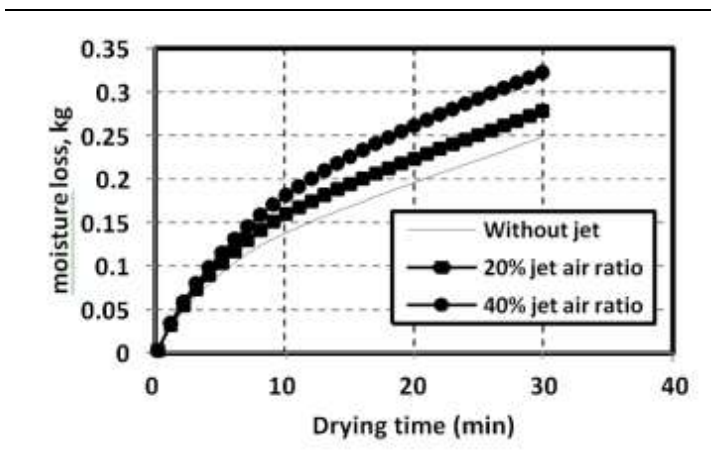

Fig. 8 Moisture loss versus drying time at various jet air ratio for $T_{i}=60^{\circ} \mathrm{C}$ and $u_{i}=2$ $\mathrm{m} / \mathrm{s}$

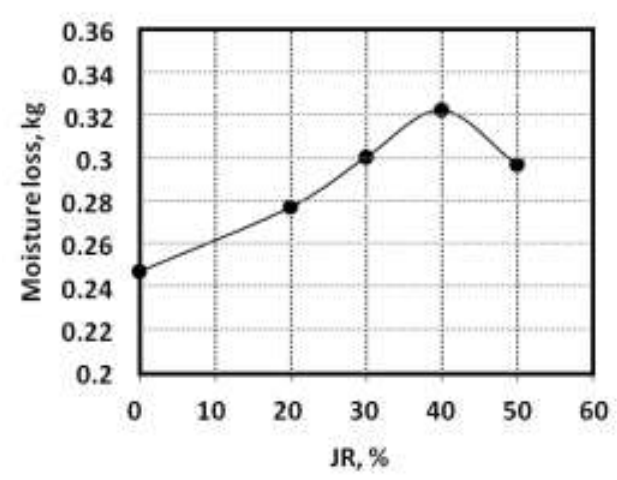

Fig. 9 Moisture loss versus jet air ratio for $T_{i}=60^{\circ} \mathrm{C}, u_{i}=2 \mathrm{~m} / \mathrm{s}$ and $\mathrm{h}_{b}=25 \mathrm{~cm}$

\section{Effect of jet height}

The jet pipe was designed to be movable in vertical direction to adjust the position of jet orifice with respect to the air distributor. The Effect of jet orifice height above the distributor on drying process has been investigated and the obtained results are plotted in Figs. 10 and 11. Fig. 10 shows the moisture loss of the fenugreek particles versus time at various jet heights. The results demonstrate that the drying performance improves with applying jetting fountain configuration excepting the case of $24 \mathrm{~cm}$ jet height where the jet orifice becomes very close to the bed surface.

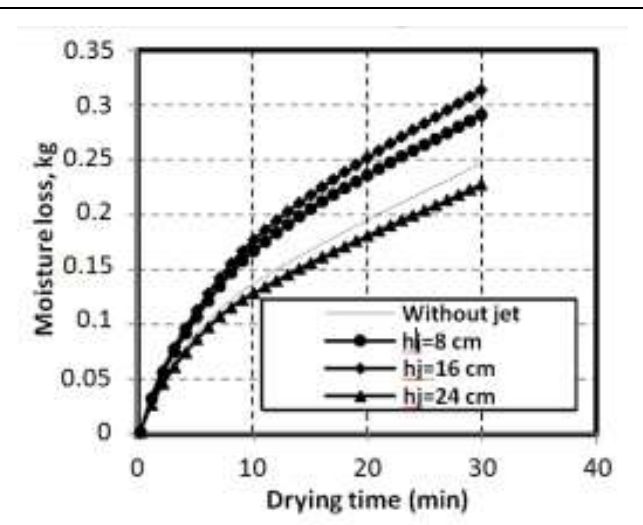

Fig. 10 Moisture loss versus drying time at various jet height for $h_{b}=25 \mathrm{~cm}$ $T_{i}=60^{\circ} \mathrm{C}$ and $u_{i}=2 \mathrm{~m} / \mathrm{s}$

Fig. 11 shows the moisture loss of the fenugreek particles versus jet height for drying time of $30 \mathrm{~min}$. The trend line is not monotonic but rather exhibits a maximum point at $12 \mathrm{~cm}$ jet height. It is evident that there is a certain jet height for each applied jet velocity at which the performance of process drying attains its optimum. It is a matter of compromise for different competitive factors. The enhancement in contact efficiency due creating a fountain of particles and reducing bubble size has positive impact. On the other side, the lower part of bed that is bypassed by jet air becomes greater which has a negative impact. 


\section{Conclusion}

An experimental study on drying process in a novel configuration of fluidized bed, namely jetting fountain fluidized bed has been carried out. The experimental tests have been also performed in the conventional fluidized bed for comparison purpose. The influences of different parameters have been tested and evaluated. Based on the obtained results and the above analysis, the following conclusions can be drawn:

- Jetting fountain fluidized bed enhances drying process. The moisture loss can be increased by up to $30 \%$ over conventional fluidized bed.

- Drying rate at the higher temperature is faster than at the lower temperature.

- The optimum jet air ratio is found to be $40 \%$ under the considered conditions.

- $\quad$ The optimal jet height is found to be at $12 \mathrm{~cm}$ under the considered conditions.

\section{References}

[1] Soponronnarit, Somchart and Prachayawarakorn, Somkiat (1994), "Optimum strategy for fluidized bed paddy drying ", Drying Technology v 12 n7 October , King Mongkut'sInst of Technology Thonburi, Bangkok, Thailand pp. 1667-1686.

[2] Oluwaleye. I.O. and Adeyemi. M.B."Experimental Evaluation of a Batch Hot Air Fluidized Bed Dryer ", International Journal of Modern Engineering Research (IJMER), Vol.3, Issue.1, Jan-Feb. 2013 pp497-503.

[3] JamshidKhorshidiand, Hassan Davari, "Experimental Study of Drying Process of COLZA Seeds in Fluidized Bed Dryer by Statistical Methods ", Advances in Chemical Engineering and Science, 2012, 2, 129-135.

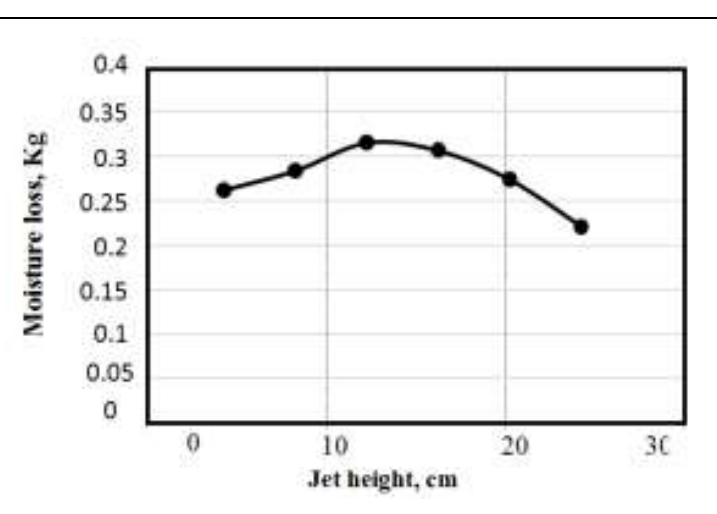

Fig. 11 Moisture loss versus jet height for $T_{i}=60^{\circ} \mathrm{C}, u_{i}=2 \mathrm{~m} / \mathrm{s}$ and $h_{b}=25 \mathrm{~cm}$

[4] Simmonds W.H.C, Ward G.T, McEwen E," The drying of wheat grain, Part 1: The mechanism of drying", Trans InstChemEng 1953; 32:265-78.

[5] V. João, F. A. Biscaia Jr., C. Evaristo and M. Giulio,"Modeling of Biomass Drying in Fluidized Bed,"Pro- ceedings of the 14th International Drying Symposium, São Paulo, 22-25 August 2004, pp.1104-1111.

[6] T. Bosteels, W. Tackaert, G. Van Stappen and P, Sorgeloos, "Improved Use of the Fluidized Bed Dryer for Artemia Cysts", Auacultural Engineering, Vol. 15, No. 3, pp. 169-179, 1996.

[7] G. Srinivas, Y. PydiSetty, "Drying behavior of uniform and binary mixture of solids in a batch fluidized bed dryer ", Powder Technology 241 (2013) pp. 181-187.

[8] TayyebNazghelichi, Mohammad Hossein Kianmehrand Mortaza Aghbashlo, "Thermodynamic analysis of fluidized bed drying of carrot cubes", Energy 35 (2010) 4679-4684.

[9] Okasha F. A novel configuration for fluidized bed. Recent Patents on Chemical Engineering 2013; 6:99-106.

[10] Okasha F. Smooth combustion of gaseous fuels in a novel 
configuration of fluidized bed. Fuel 2013; 106: 512-518.

[11] Okasha FM, Zeidan EB. Experimental study on propane combustion in a novel fluidized bed configuration. Fuel Processing Technology 2013; 116:79-84.

[12] Okasha F, Zaater G, El-Emam S, Awad M, Zeidan E. Co-combustion of biomass and gaseous fuel in a novel configuration of fluidized bed: Thermal characteristics. Energy Conversion and Management 2014; 84:488-496. 13. Okasha F, Zaater G, El-Emam S, Awad M, Zeidan E. Cocombustion of biomass and gaseous fuel in a novel configuration of fluidized bed: Combustion characteristics. Fuel; 133:143-152.

[13] Okash F, Elnaggar M, Zeidan E. Enhancing emissions reduction and combustion processes for staged-air combustion of biomass in fluidized bed.Energy Fuels 2014, 28, 6610-6617.

[14] Zeidan EB, Okasha FM. Controlling the freeboard temperature applying a novel design of fluidized bed.Journal of the Taiwan Institute of Chemical Engineers 2014; 45 (4), 1347-1353 